\title{
Metron, a century old, but it does not show it
}

\author{
Giovanni Maria Giorgi ${ }^{1}$
}

Published online: 15 July 2020

(c) Sapienza Università di Roma 2020

Many years ago, when I was at the University of Siena, I had the chance to read an interesting paper by Carlo Benedetti (1984) in the wonderful library of the Faculty of Economics located in the suggestive Gothic crypt of the former Saint Francis convent. In this paper, the author debated on how well Corrado Gini was internationally known for the inequality index $(G)$ and the mean difference $(M D)$ but less for other original scientific contributions.

In fact, although $G$ and $M D$ caused some interest at the beginning of last century, they were only a (limited) part of his scientific research and, according to Benedetti, not the most significant one. Among other relevant results we may recall "Gini's identity" as referred to by Ragnar Frisch (1936) when analyzing the contribution of Gini (1924) to index number theory. Benedetti (1984, pp. 7-8) also showed how the Konüs index is a direct consequence of "Gini's identity" and how the latter builds a solid bridge between statistical and economic theory; on the subject see also Benedetti (1966).

Despite Gini's original contributions in various fields, he remained particularly fond of the $G$ inequality index and he was so proud of it that he could not even tolerate that someone could belittle it in any way. The reaction of Gini and his collaborators was particularly strong when Bonferroni (1930) introduced the inequality index $B$ in "Elementi di Statistica Generale", a textbook for undergraduate students at Bocconi University in Milan, where he also showed how to derive concentration measures that are as simple to use as the Gini ratio. The possibility that another measure of inequality could somewhat obscure the concentration ratio $G$ led Gini and his entourage to strongly try to prevent the diffusion of Bonferroni's $B$ index.

In particular, when an extended version of his book (Bonferroni 1940) was published, the critical reaction of Gini's collaborators became more evident. Boldrini (1942), for example, started discussing differences between Statistics made by statisticians and Statistics made by mathematicians.

The statistician Boldrini (1942, pp. 337-339) noted that the book "does not consider Statistics as we understand it, that is, as a system of direct methods to solve practical problems". Boldrini (1942) concluded by underlining how Bonferroni was at odds with his view of Statistics because, "in the opinion of statisticians, relations are relations between things. What we cannot investigate barely touches us and does not affect us like a mathematician who has an entirely different education than ours" (see also Giorgi 2011).

Giovanni Maria Giorgi

giovannimgiorgi@gmail.com

1 Department of Statistical Sciences, "Sapienza" University of Rome, Piazzale Aldo Moro 5, 00185 Rome, Italy 
The controversy was highly specious, as can be deduced from the consideration Bruno de Finetti (1961) had for Bonferroni. He saw Bonferroni as a mathematician who was not limited to formalism but tried to give concreteness to his work and was also competent in fields such as economics, statistics and finance.

Overtime the way Gini and his collaborators considered Statistics substantially changed. Nevertheless, whoever the Editor of Metron has been after Gini, the journal has continued to maintain its tradition of publishing methodologically rigorous articles, which are also practice-oriented. In particular, to limit the use of mathematical formulation by itself, the authors were always asked to, at least, discuss the applicability of the proposed method to real phenomena even in contexts unthinkable to his founder.

Concerning the use of the Gini index in fields that were simply unconceivable to his author, we consider it as appropriate to recall some scientific work by scholars who are neither statisticians nor economists. In particular, a recent paper published in the Annals of Physics (Eliazar 2018) discusses how inequality indices can be used not only in human societies but can be also applied to general count, length, area, volume, mass, energy, and duration distributions.

I must say that, although I had graduated in Statistics and Actuarial Sciences at the University of Rome (today Sapienza University), I did not know much about Corrado Gini, founder of the Faculty of Statistical Sciences in 1936, as his former collaborators, including Vittorio Castellano and Carlo Benedetti, did not go into much details about his personality and scientific work.

Thus, forced by a great curiosity, I started approaching and studying Gini's work from different points of view. It then became immediately clear to me how important it was for him to disseminate the objectives and results of scientific research carried out under his direction or by his team. This also explains his commitment to establishing new scientific journals to disseminate the results of the so-called Italian Statistical School.

In this context, the journal Metron has a specific role. Its first number was published in July 1920 with a golden-yellow cover in a liberty style full of floral ornamental motifs and it included, among others, papers by L. March, E. Czuber, FY Edgeworth, G. H. Nibs, J. Burdon, F. P. Cantelli and Gini himself.

It is also worth mentioning that in 1970 Benedetti, reading through The American Statistician, found an article by Churchill Eisenhart (1970) that celebrated the 50th anniversary since Metron's first issue. Benedetti (1970, p. 34) then wrote that "it was as if a stranger had reminded me, just in time to avoid a bad impression, the birthday of a beloved person".

As far as the hundredth anniversary is concerned, the Metron staff has not been caught unprepared. In fact, Prof. Marco Alfò, current Editor in Chief, had the event on his agenda since December 2017 when, at the end of my term as Editor in Chief, I left the management of the journal and invited him to plan any action for a successful celebration. I must say that not only did he not forget it, but, wisely, he decided to dedicate the entire 2020 volume (number 78) to this anniversary, considering the classic themes of inequality so close to Gini (to whom this issue is dedicated), as well as other topics that are representative of today's statistical research.

Professors Jacques Silber, Roberto Zelli and I myself have been invited to guest edit this issue. The issue includes six papers reporting fresh contributions made by well-known researchers in the field of inequality measurement and related topics. It clearly cannot cover all frontiers but gives a glimpse of some active work in this field. The manuscripts were submitted upon invitations from the guest editors and followed the peer-review process of the Journal. 
A century has passed and Metron is not only still active and available to scholars but gained further followers also thanks to the international publisher Springer. It is precisely the case to say that "it is hundred years old but it looks younger".

\section{References}

Benedetti, C.: A proposito del Centenario della nascita di Corrado Gini. Metron 42(1-2), 3-19 (1984)

Benedetti, C.: Sulla "identità di Gini" e l'omogeneità delle funzioni di utilità e di produzione. Metron 25(14), 291-309 (1966)

Benedetti, C.: A proposito del cinquantenario di Metron. Metron 73(1-4), 34-38 (1970)

Boldrini, M.: Recenti trattati italiani nelle discipline statistiche. Statistica 2(4), 335-348 (1942)

Bonferroni, C.E.: Elementi di Statistica Generale. Seber, Firenze (1930)

Bonferroni, C.E.: Elementi di Statistica Generale. Gili, Torino (1940)

De Finetti, B.: Commemorazione del Prof C.E. Bonferroni, Università di Firenze, 8 Maggio 1961. Subsequently Published in Giornale di Matematica Finanziaria, 1964 46, 5-24 (1961)

Eliazar, I.: A tour of inequality. Ann. Phys. 389, 306-332 (2018)

Eisenhart, C.: Anniversaries in 1970 of interest to statisticians. Am. Stat. 24(1), 25-28 (1970)

Frisch, R.: Annual survey on general economic theory: the problem of index numbers. Econometrica 4(1), $1-38$ (1936)

Gini, C.: Quelques considérations au suject de la construction de nombres indices et des questions analogue. Metron 4(1), 3-162 (1924)

Giorgi, G.M.: Corrado Gini: the man and the scientist. Metron 69(1), 1-28 (2011)

Publisher's Note Springer Nature remains neutral with regard to jurisdictional claims in published maps and institutional affiliations. 